\title{
Reflexiones sobre la naturaleza humana en el pensamiento de Aristóteles
}

\section{(Considerations upon human nature in Aristotle's thought)}

\author{
José Javier Benéitez Prudencio \\ Universidad de Castilla-La Mancha \\ josejavier.beneitez@uclm.es
}

Recibido: 14 de enero de 2011

Aceptado: 7 de septiembre de 2011

\section{Resumen}

Aristóteles sostiene que sólo los humanos pueden hablar y que tal capacidad es un elemento propio de su humanidad. Establece también que el habla sirve para distinguir lo correcto y lo incorrecto, y acaba diciendo que es la participación en este orden de cosas lo que hace a una ciudad. En último término, el ser humano que no está en una polis ¿en realidad no sería tal? ¿Podría tener el ser humano menor consideración, entonces, que una estatua con forma humana?

Palabras clave: Aristóteles, ser humano, 'alma' (psychế), cuerpo, funcionalismo, ciudadano, homonimia.

\begin{abstract}
Aristotle says that only humans can speak and the speech capability is a proper criterion of humanity. Speech is also designated by Aristotle to indicate the right and the wrong. He finishes by saying that it is partnership in these things that makes a city. Ultimately a human being who is not in a polis, would not really be a human being at all? Would this human being then be no more human than a statue with a human form?
\end{abstract}

Keywords: Aristotle, human being, 'soul' (psychế), body, functionalism, citizen, homonymy. 


\section{A modo de introducción: ¿peces que vuelan y seres parlantes procedentes de Júpiter?}

Para Aleksandr Herzen (1956, p. 94), hacerse la pregunta sobre si los humanos somos libres o no era igual que plantearse si los peces pueden volar. Se han vertido ríos de tinta acerca de la libertad, en cambio, poco se ha dicho sobre los alardes voladores de los peces, o al menos de ciertas clases de ellos, más allá de los cuentos o las fantasías literarias y -claro es- de los estudios científicos que hubiere. La comparación suena a frivolidad. Sin embargo, mientras Herzen se sintió movido a tratar sobre la libertad, un pensador tan polifacético como Aristóteles se mostró mucho más inclinado a investigar las especies animales, y como zoólogo justificó por qué los animales acuáticos no pueden volar. Habría mantenido esta misma consideración, aun cuando hubiese sabido que dentro del 'género' (génos) ${ }^{1}$ de los peces existen algunos voladores (exocoetidae) que hoy en día estudian sus sucesores. Aristóteles, que no sólo fue zoólogo, nos ofrece una compleja argumentación de por qué los peces no vuelan inscrita dentro de su concepción del mundo natural. En este sentido, explica que lo que decimos que es 'pluma' en el ave, por analogía es 'escama' en el pez (cf. Partes de los animales [PA] I 4, 644 22-23). Cada género de las diversas especies animales poseen unos rasgos y atributos naturales que le son 'propios' (idia), y constituyen sus 'diferencias' (diaphorai), sirviendo para distinguirlas unas de otras. Las aves se caracterizan por tener patas y alas, mientras que los peces no -salvando, repito, la analogía 2 . Tal ser vivo con patas y alas es un ave y no un pez. Cada clase de animal posee 'por naturaleza' (katà phýsin) sus 'facultades' (dynámeis) y cada individuo dentro de cada clase o grupo está llamado a cumplir una 'función' (érgon) que le es propia 3 .

Aristóteles es consciente de "la admirable diversidad" que reina en el mundo natural, pero reconoce lo siguiente: "se podría establecer que las plantas pertenecen a la tierra, los seres acuáticos al agua y los terrestres al aire" (Reproducción de los animales [GA] III 24, 761b 13-15). En Partes de los animales establece, además, que el volar pertenece a la "esencia [ousía]" de las aves (PA IV 12,693b 13), mientras que el nadar en el medio acuático a la "esencia" de los peces ( $P A$ IV 13, 695 b 18). Dichos principios se mantienen aun cuando se descubre que existen, en efecto, aves que no pueden volar y (aunque no alude a ello, podríamos añadir sin forzar su pensamiento) peces capacitados para abandonar siquiera momentáneamente su

\footnotetext{
${ }^{1}$ Adviértase que en el Corpus aristotélico se hace a veces un uso impreciso de génos y 'especie' (eîdos) -cf. Lennox (1986, p. 348) y Ackrill (1997, p. 166).

2 Para las diferencias entre los distintos géneros animales, véase la concisa exposición que hace Greg Bayer (1998, pp. 494-496).

3 Acerca del sentido de la teleología aristotélica en el ámbito de la 'ciencia natural' (epistême physikê), puede seguirse la monografía de Monte Ransome Johnson (2005, pp. 131-286).
} 
medio natural. En este mismo tratado zoológico Aristóteles se pronuncia sobre la escasa utilidad que a su juicio tiene el establecimiento de taxonomías para el reino animal -hace alusión a las tablas utilizadas en la Academia con las que los discípulos de Platón practicaban el método de la división (diairesis) ${ }^{4}$ :

No conviene separar cada género, por ejemplo las aves, unas en una división [diairései], otras en otra, como las tienen las Tablas de División; allí, en efecto sucede que unas están clasificadas entre los animales acuáticos y otras en otro género. De acuerdo con esa semejanza se aplica el nombre de ave, según otra el de pez ( $P A$ I 2, 642 b 10-13).

El estudio de la naturaleza en su conjunto constituyó el titánico empeño emprendido por parte de Aristóteles y su escuela (cf. PA I 5, 644b 22-645a 36), pero el Estagirita habló más y mejor de lo que le resultaba cercano y más conocido: el ser humano. En realidad, se le ha achacado que sus investigaciones naturales adolecen de antropomorfismo (cf. Sedley 1990, pp. 179-196). Acabamos de ver que cada una de las clases animales posee algún rasgo o principio natural que las caracteriza. También el ser humano constituye un génos específico (cf. Investigación de los animales [HA] I 6, 490b 16-19) y como el ser vivo más sublime de entre todos los que existen, al menos en el ámbito sublunar ${ }^{5}$, posee también unos rasgos que son propios de su género. Al hilo de la especifidad del ser humano aristotélico, Stephen Clark propuso hace algunos años un ejemplo que, sin duda, resulta sugerente para los lectores contemporáneos, más o menos familiarizados con la ciencia ficción y con la imaginación de seres procedentes de otros planetas y galaxias. Sin embargo, la hipótesis que plantea con su ejemplo es de dudosa utilidad para alcanzar a comprender nítidamente el pensamiento de Aristóteles. Clark se refiere a unos habitantes del planeta Júpiter, de aspecto arácnido ('forma': morphế, eîdos) y constituidos de hidrocarbono ('materia': hylế). El punto crucial es éste: dichos jovianos serían humanos - dice Clark (1975, p. 25)- "si ellos pudieran conversar con nosotros y nosotros con ellos". Según este tipo de fantasías, los extraterrestres son casi siempre presentados de manera radicalmente diferente respecto del género humano, al menos por lo que respecta a su aspecto y fisiología, no así en cuanto a sus costumbres y a la posibilidad de mantener una comunicación con ellos. En relación a esto último, uno de los pasajes más famosos e influyentes de la Política [Pol.] (cf. I 2, $1253^{\mathrm{a}}$ 9-14) establece que el 'ser humano' (ánthrôpos) es el único ser vivo que está

\footnotetext{
4 Pierre Pellegrin (1982), en su magistral estudio sobre la biología de Aristóteles, destacó que aunque el afán del Estagirita no fuera taxonómico las clasificaciones cumplen una función esencial a la hora de establecer las definiciones de los animales y sus diferencias.

5 Nos plegamos a la tradición. El término 'sublunar' no aparece en el Corpus, pero lo utilizaron los comentaristas del Aristóteles desde la misma Antigüedad. Por otro lado, la reciente exposición de Catherine Osborne (2007, pp. 98-132) sobre la scala naturae aristotélica puede resultar de interés. La autora critica el 'absolutismo antropomorfista' con que tradicionalmente se ha interpretado ésta.
} 
dotado con la capacidad de hablar-pensar (lógos). Si estamos de acuerdo con Clark, seríamos proclives a otorgar la humanidad a estos jovianos parlantes. Ciertamente, la noción de lo humano ha cambiado desde el tiempo de Aristóteles a nuestra parte, pero el problema es que en términos aristotélicos la hipótesis de que dichos seres se expresen en un lenguaje humano resulta desconcertante porque a la vista del Corpus - no sólo del libro I de la Política- se hace muy difícil imaginar que pudieran hablar y ser, por tanto, humanos de verdad. Más adelante nos adentraremos en ello.

Aristóteles no se refiere a ningún joviano, pero sí alude de pasada a unos animales que habitan en la luna (cf. Movimiento de los animales 4, 699b 19). Una raza de selenitas no tendría nada de especial, dado que habitarían en el límite del universo en que todavía rige la ley natural de la generación y la corrupción. Por otro lado, no era extraña en las fuentes griegas desde el pensamiento presocrático hasta Luciano de Samosata la creencia de que la Luna estaba habitada. Supongamos contra la argumentación aristotélica que estos jovianos de hidrocarbono que imaginó $\mathrm{S}$. Clark pudieran hablar, inmediatamente asaltarían otra clase de preguntas: ¿sería posible que hubiera seres con forma de araña y de hidrocarbono en las regiones de las órbitas celestiales, en donde los únicos vivientes son los seres incorruptibles, de naturaleza divina? No haría falta irse hasta Júpiter, de nuevo, la cultura griega estaba familiarizada con animales no humanos que hablan y se muestran arteros y sagaces (junto a sus contrarios), como los humanos a quienes representan. Sin embargo, las fábulas eran cuentos que trasponían el carácter humano a unos tipos de animales. También eran archiconocidas ${ }^{6}$ otra clase de historias, como el suceso extraordinario que aconteció a los compañeros de Odiseo que tras el hechizo de Circe quedaron convertidos en cerdos. A pesar de que no podían hablar sí conservaban la "mente" o nous, que es también lo propio del humano (Homero, Odisea X, 239240). El mismo Aristóteles concede "un habla como los hombres" al "pájaro de la India" o loro, pero en este caso excepcional de las dotes de un animal subhumano que habita en una remota región del mundo se trata de una mera "imitación" de las palabras humanas (HA VIII 12, 797b 28-29).

No será ésta la ocasión para ponerse a discurrir sobre si los griegos creyeron o no en sus propios mitos - en todo caso, quien se muestre interesado deberá remitirse al estudio de Paul Veyne (1983). Sólo pretendo subrayar que ya existía por aquel entonces en que vivió Aristóteles una diferente apreciación entre dejarse llevar por lo que transmiten los cuentos - tal vez, persuadirse de ellos- y una indagación 'científica', esto es, una investigación que pretende hacerse con rigor crítico sin mediación de las historias fabulosas tradicionales, aunque tal vez no lo lograse del todo

\footnotetext{
${ }^{6}$ No me refiero sólo a que la gente se conociera de memoria los versos homéricos, sino al hecho, quizás, menos conocido de que el episodio al que aludo sirve de motivo pictórico en la popular pintura ceramográfica de figuras rojas. Así, se representa, por ejemplo, en el kýlix del Pintor del Polifemo del Museum of Fine Arts de Boston.
} 
- esa es otra cuestión. El rigor crítico al que me refiero da comienzo como es sabido con Jenófanes y alcanza las propias reflexiones de Platón. El tipo de 'indagación' o 'investigación' (historía) que persiguió Aristóteles destierra, también, el cuento (mythos) y el prodigio o la maravilla (thaumásia) -cf. Metafísica [Metaph.] I 2, 982b 17-19-, y en concreto, su investigación zoológica (bajo cuyo término se comprende una plasmación de sus principios físicos, 'psicológicos' y metafísicos7) se guía por sus propias preocupaciones e intereses teóricos (cf. Lloyd 1986, p. 54). El lector podrá achacarme -y tendrá razón- el que me haya adelantado de una manera impetuosa a la conclusión: creer que hay humanos en Júpiter sería dar fe irracionalmente a los cuentos, y Aristóteles fue un 'científico' riguroso que pretendió desterrar esta clase de explicaciones. Espero que en las páginas que siguen mi ímpetu inicial deje paso a una exposición ilustrativa del pensamiento aristotélico en relación con la naturaleza del ser humano que justifique, empero, esto que acabo de decir. Debemos preguntarnos, en primer lugar, qué es el 'ser humano' (ánthrôpos) para Aristóteles.

\section{La forma humana}

Aristóteles dice que "la forma del hombre [anthrốpou eîdos] se manifiesta siempre en carnes, huesos y partes de este tipo" (Metaph. VII 11, 1036b 4). Esto zanjaría la disquisición de haber otros seres humanos hechos de materiales que no sean éstos a los que se refiere el Estagirita. Sin embargo, Bernard Williams (1986, p. 192, n. 2) dudó que este pasaje "signifique lo que quiere decir". A su entender, y a pesar de lo que se lee en el texto de la Metafisica, podría abstraerse la forma de la materia humana concreta. Lo más prudente sería ajustarnos a la literalidad del texto, con lo cual dicha separación se hace imposible de sostener (cf. Heinaman 1979, p 261). Aristóteles determina que la forma humana "siempre" se realiza en esas partes materiales a las que él mismo se ha referido. El pasaje en cuestión de la Metafisica trata sobre la posibilidad de 'separar' (chôrizô) la 'forma' (ếdos) de la 'materia' (hylế), pero no hay que perder de vista que se dan, según Aristóteles, formas en que dicha separación es posible y otras, como la forma humana, en que no. En el caso de los círculos y los triángulos, a diferencia del ser humano, la " $<$ separación $>$ parece posible" (ibid. 6-7). Por tanto, en este caso, puede abstraerse de la forma del círculo o del triángulo la materia con que tales figuras geométricas están hechas, así el bronce, la piedra o la madera:

Por ejemplo, el círculo $<$ se realiza $>$ en bronce, en piedra y en madera, en tales casos parece estar claro que ni el bronce ni la piedra son, en absoluto, una parte de la entidad

7 Cf. Balme (1986); Lloyd (1995, pp. 38-66) y, sobre todo, Furth (1988, passim). 
[ousías] del círculo, dado que éste puede separarse [chôrízesthai] de ellos" (Metaph. VII $11,1036^{\text {a } 30-34) . ~}$

En Acerca del alma [DA] (I 3, 407b 13-24), Aristóteles se refiere de manera contundente a la "absurda" creencia de los pitagóricos sobre la trasmigración de las almas según la cual el alma se separa del cuerpo tras la muerte para volver a anidar en un nuevo cuerpo ulteriormente. En términos aristotélicos, los pitagóricos creían poder separar la materia (el cuerpo) de la forma (el alma), pero Aristóteles comenta de manera despectiva que los pitagóricos olvidaron definir qué es el cuerpo y, además, que "cada cosa posee una forma y una estructura peculiares".

El escueto comentario de Bernard Williams en una nota al margen de su investigación de la teoría hilemórfica nos deja sumidos en la perplejidad. Quizás, podría arrojarse un poco de luz a sus palabras si tuviéramos en cuenta el hecho de que Aristóteles reconoce en el capítulo precedente, el 10, de este libro VII de la Metafisica que "una cosa es la materia, otra la forma y otra el compuesto de éstas" (Metaph. VII 10, 1035 1 -2), y que lo esencial, además, es la forma y lo accidental la materia (cf. ibid. 7-9; Física [Ph.] II 2, 194b 9-13). Debido a los adelantos de hoy en las técnicas de la medicina ya no resulta extraño que la materia con que naturalmente están hechos todas nuestras partes y órganos pueda ser otra distinta. Lo importante en una operación de transplante de un órgano natural por otro artificial es que continúe cumpliendo la misma función (érgon) que tenía el órgano que ha sido reemplazado. Para nosotros, no hay duda de que aquél que ahora es un órgano artificial continúa siendo la misma parte del ser humano, aunque no esté hecho de carne y de otros tejidos similares (cf. Frey 2007, p. 198), pero ¿qué es lo que habría pensado Aristóteles? Este supuesto del órgano artificial transplantado lo barajan las interpretaciones funcionalistas de Aristóteles. El funcionalismo surgió en medio del debate interpretativo sobre la teoría 'psicológica' de la mente ${ }^{8}$, y en la que desde luego no es seguro que debiera incluirse a Bernard Williams. El crítico más incisivo del funcionalismo, Myles Burnyeat, antiguo alumno y luego amigo de Williams, es el autor de uno de los ensayos contra los presupuestos funcionalistas que más polémica ha levantado en las últimas décadas - cf. Burnyeat (1995a, pp. 15-26), y para sus ulteriores consideraciones, Burnyeat (1995b, pp. 421-434). John Ackrill (1997: 163-178), influyente colega de Williams en Oxford, también se mantuvo lejos de una interpretación funcionalista del 'alma' o psychế en Aristóteles. De entre todos los puntos principales en que reparan los intérpretes del funcionalismo son sólo dos los que interesa destacar a nuestros propósitos (cf. Nussbaum y Putnam 1995, p. 33):

\footnotetext{
8 Véase Nussbaum y Putnam (1995). El estudio que hacen Alan Code y Julius Moravcsik (1995) ofrece una buena evaluación del funcionalismo aristotélico y su diferenciación respecto a las teorías funcionalistas contemporáneas -señaladamente, la de Hilary Putnam.
} 
i) Los seres vivos están dotados de gran plasticidad material.

ii) La materia a la que alude la línea 4 de Metaph. VII 11, 1036 b es necesaria mente contingente, dado que lo esencial es la forma (cf. ibid. VII 10, 1035 7-9).

Debiera tenerse claro que preguntarnos por la materia del ser humano o de alguno de sus órganos en concreto no es lo mismo que preguntarse por la materia en que se compone, por ejemplo, una cama de madera o alguna de sus partes homeómeras -Frey 2007, p. 202. Por tanto, como reconoce James Lennox (2001, p. 183), si los funcionalistas se basan en que los cuerpos compuestos por órganos poseen una estructura biológica que está únicamente caracterizada por la función que cumplen, "Aristóteles no podría ser sólo un funcionalista". Por otro lado, no es muy difícil saber cuál habría sido la respuesta de Aristóteles ante un órgano transplantado. Un órgano o una parte del cuerpo artificiales, sólo sería tal órgano o parte por el nombre, es decir, por homonimia. La homonimia la define Categorías (I 1, 1 $\left.{ }^{\text {a }} 1-6\right)$ de esta manera:

Se llaman homónimas las cosas cuyo nombre es lo único que tienen en común, mientras que el correspondiente enunciado de la entidad es distinto [Homốnima légetai hôn ónoma mónon, hó dè katà toúnoma lógos tês ousías héteros], v. gr:: 'vivo' dicho del hombre y dicho del retrato; en efecto, ambos tienen sólo el nombre en común, mientras que el correspondiente enunciado de la entidad es distinto; pues si alguien quisiera explicar en qué consiste para cada una de esas cosas el ser vivas, daría un enunciado propio para cada una.

En el Corpus se recurre muchas veces a la homonimia. En Acerca del alma (cf. II 1, 412b 19-24) $)^{9}$ se explica que llamamos 'ojo' al de una estatua o de una pintura que representan una figura humana, aunque sabemos que sólo guardan relación con el auténtico órgano natural la palabra 'ojo'. El órgano de la visión es aquél con el cual somos capaces de ver, salvo por alguna disfunción o 'privación' (stérêsis) -cf. Metaph. IX 1, 1046 29-35. El funcionalista puede alegar que, a diferencia del ojo de bronce, de piedra o pintado, al menos un corazón artificial (por ejemplo) continúa cumpliendo las funciones propias de un corazón natural. Pero, en realidad, para Aristóteles sería imposible esperar que el órgano artificial cumpliera la misma función que el natural trasplantado (cf. Berryman 2007, p. 36). Por supuesto, Aristóteles nada podía saber sobre la posibilidad de hacer trasplantes de corazón ni de otro tipo. Además, según indicamos antes, eso de otorgar crédito a la 'ciencia ficción' - al modo defendido por los funcionalistas para explicarnos el pensamiento

\footnotetext{
${ }^{9}$ Este ejemplo, junto a otros del mismo tenor, los ha tratado pormenorizadamente Christopher Schields en su monografía sobre la homonimia (Schields 1999, pp. 131-154).
} 
aristotélico- supondría dejar al Estagirita en las redes de los cuentos y de los prodigios. Bastará echar una mirada al repertorio cultural griego para terminar de cerciorarnos sobre la impropiedad y el anacronismo de esta faceta del funcionalismo. Hay mitos que pueden servirnos muy bien al caso, dado que aluden o se refieren a partes del cuerpo artificiales. Así, aquel que refiere el crudelísimo festín de Tántalo. Este hijo de Zeus convidó a los dioses a un banquete en el cual ofreció como bocado a su hijo, Pélope. Los dioses que casi todo lo pueden castigaron a Tántalo y resucitaron al joven descuartizado, rehaciéndolo en una forma todavía más hermosa. Luego le suplantaron el hombro que le había comido la descuidada Deméter por otro de marfil (cf. Píndaro, Olímpica I, 37-41; Ovidio, Metamorfosis VI, 404-411). Pero no sólo había mitos; se contaban también extraordinarios prodigios, como el que se refiere al muslo de oro de Pitágoras. Aristóteles mismo es quien recoge esta noticia en una referencia que conservamos por el paradoxógrafo Apolonio (cf. Sobre los pitagóricos, fr. 1a). Tanto Pélope como Pitágoras eran seres humanos muy poco parecidos al común de los mortales, el uno pertenecía al tiempo de los héroes mientras que al otro lo consideraban un ser semidivino. Y fuera de los mitos como el de Tiestes y Pélope o de las historias legendarias como ésta relacionada con Pitágoras, no hubo lugar a procedimientos quirúrgicos con empleo de prótesis tan singulares, hechas de materiales nobles (el marfil y el oro estaban vinculados con el culto religioso). En las técnicas médicas griegas en general, y no sólo en el Corpus aristotélico en particular, el implante de unas prótesis de estos u otros materiales era del todo impensable; la práctica médica era fundamentalmente reparadora y evacuante (cf. Laín Entralgo 1987, pp. 351, 353), y sólo en casos extremos de auténtica necesidad recurría a las prácticas quirúrgicas. Aristóteles sólo llega a mencionar en Acerca del alma -y nada seriamente- la hipótesis de que si pudiera reemplazarse el ojo de un anciano por el de un joven, el anciano dejaría de ver con su vista cansada, que es la propia de su edad (cf. $D A$ I 4,408 b 21-22) ${ }^{10}$.

La identidad de un órgano o una parte del cuerpo humano en sí misma no depende de la posesión de unas funciones propias acordes con su naturaleza, sino de la identidad de esa 'parte' (méros) con el 'todo' (hólos) que constituye el compuesto

\footnotetext{
10 A la vista de lo expuesto se comprenderá por qué no nos mostramos nada proclives a la interpretación funcionalista. Ésta, no obstante, encuentra cierto acomodo en el Corpus aristotélico: en la Mecánica, una obra que no suele atribuirse al fundador del Perípato, se adelanta un motivo que -como se sabe- desarrollará el mecanicismo moderno. La idea que preside este pequeño tratado es la siguiente: el funcionamiento mecánico puede conseguir imitar los movimientos naturales. De esta manera, según el autor de la Mecánica, no existe diferencia alguna entre un tipo de movimiento y otro. Repárese, también, en el hecho de que esta explicación, en realidad, es ajena a lo que se explica en la Física. Por otro lado, encuentra sus precedentes en los mitos sobre el origen o el desarrollo de las técnicas y sobre artilugios mecánicos, como los de Prometeo, Hefesto y Dédalo -cf. Kris y Kurz (1934, pp. 89-90). Agradezco al revisor anónimo el que tan constructivamente me haya hecho reparar en la Mecánica y en la cita al libro de Ernst Kris Y Otto Kurz.
} 
humano (cf. Frey 2007, p. 191). No existe parte del cuerpo de un ser vivo, mantiene Aristóteles (cf. GA I 19, 726b 22-24), en donde no exista el principio vital o 'alma' (psychế), y en caso contrario sólo guardarán el nombre respecto de la parte del cuerpo u órgano vivo -serán, por tanto, homónimos. La gran lección del capítulo 1 del libro II del tratado Acerca del alma es que la psychế es la 'forma' (eîdos) del cuerpo que tiene vida, y constituye su 'esencia' (ousía). En realidad, siguiendo a J. Ackrill (1997, p. 163), en dicho capítulo se distinguen tres concreciones de la definición de psychế como 'forma' atendiendo a la teoría del 'acto' o 'actualización' (enérgeia) y la 'potencia' (dýnamis) -entiéndase que Ackrill parte del presupuesto aristotélico de relacionar la 'actualización' y la 'potencia' con la 'materia' y la 'forma', respectivamente ${ }^{11}$ :

i) La psychế es la forma del cuerpo que posee potencialmente vida.

ii) La psychế es la actualización primera del cuerpo que posee potencialmente vida.

iii) La psychế es la actualización primera del cuerpo que posee órganos.

En Identitity and spatio-temporal continuity, David Wiggins (1967, p. 48) pensó que el 'alma' en Aristóteles, al ser siempre de un cuerpo que tiene vida, equivalía a la materia de la que está hecha: "a su carne y sus venas" -escribe él. Poco después le llovieron las criticas por ésta y otras explicaciones que hizo fundándose en el pensamiento aristotélico, como la del propio Ackrill (1997 [or. 1973], pp. 163, 165). Siguiendo cierta tradición, Wiggins había convertido, además, al 'ser humano' de Aristóteles (el ánthrôpos) en 'persona', y lo identificó cartesianamente con la 'mente' (cf. Gill 1990, pp. 7, 138-139; Frede 1995, pp. 93-94). En cambio, Wiggins no se equivocó al establecer la relación entre 'alma' y 'vida'. El capítulo 2 de Acerca del alma establece:

Lo animado se distingue de lo inanimado por el vivir [diôristhai tò émpsychon tou apsýchou tô zến]. Y como la palabra 'vivir' hace referencia a múltiples operaciones, cabe decir que algo vive aun en el caso de que solamente le corresponda alguna de ellas, por ejemplo, el intelecto [nous], sensación [aisthêsis], movimiento y reposo locales [kínêsis kai stásis he katà tópon], amén del movimiento entendido como alimentación [trophề], envejecimiento [phthísis] y desarrollo [aúxêsis] (DA II 2, 413ª 21-25).

Para Aristóteles el alma es, entonces, lo animado; también dice que "el ser es para los vivientes el vivir, y el alma es su causa y principio [tò dè zên tô̂s zôsi tò einaí estin, aitía dè kaì archề toútou hế psychê]" (ibid. 4, 415b 13-14). Sin embargo, la 'vida' (zến) no tiene un sentido unívoco, es decir, que estar vivo tiene diver-

11 No obstante, Jennifer Whiting (1995, pp. 88-91) ha hecho una revisión de la exposición de Ackrill. 
sos niveles de alcance o de significación. Existen formas de vida que solamente cumplen con todas o al menos con alguna de las referidas funciones u operaciones. No resultará ocioso enumerarlas otra vez: intelecto, sensación, movimiento y reposo local, movimiento entendido como alimentación, envejecimiento y desarrollo. El caso ínfimo lo constituyen las plantas (ibid. 2, 413 a 26 ). Las plantas tienen almavida (psychế) porque "poseen en sí mismas la potencia [dýnamin] y el principio [archền]". La psychế es, por consiguiente, autónoma, pues posee el principio interno del cambio. Pero las plantas tienen sólo la facultad o la potencia del movimiento entendido como alimentación; en ellas "no se da ninguna otra potencia del alma" (ibid. 31-35). Fuera de esta forma de vida ínfima se encuentra la vida animal, y "el animal lo es primeramente por la sensación". Aquellos animales, aunque "ni se muevan ni cambien de lugar, pero posean sensación, los llamamos animales $[z \hat{o} a]$ y no simplemente vivientes [zên mónon] (sc. las plantas)" (ibid. 413b 2-4). Cada una de estas facultades y operaciones definen el alma (cf. ibid. 13), y bien "o constituye un alma o una parte del alma" (ibid. 14). Para el animal, la facultad de alimentación constituye sólo una parte de su alma, mientras que para una planta toda. Por último, Aristóteles establece que la operación más excelsa que se da en el alma de un ser vivo es la intelectiva, no obstante ésta exclusivamente la poseen los animales humanos (cf. Pol. I 2, 1253 9) -dejamos al margen de nuestro tratamiento el caso de la divinidad. Aristóteles reconoce, también, que las partes del alma "no se dan separadas [chôrízesthai] como algunos pretenden12" (DA II 2, 413b 27-28), salvo en el caso del intelecto, a pesar de lo cual "la cuestión no es clara" (ibid. 25-26).

En resumen, existen tres tipos de psychai, que ordenadas jerárquicamente según la escala natural se corresponden con la forma de vida vegetal, animal y humana. Veamos a continuación brevemente por qué el ser humano es el más excelso de todos los animales que existen.

\section{Dones naturales: la palabra y la polis}

El humano, ese "animal mortal, con pies, bípedo, sin alas" (Analíticos Segundos II 3, 92a 1-2), constituye para Aristóteles "lo mejor del cosmos" (Ética nicomáquea [EN] VI 7, 1141a 24). Distintos pasajes del Corpus se encargan de ponerlo en evidencia. Citaremos algunos, aunque acabo de aludir al primero de ellos, al decir que el hombre es el único con la capacidad de hablar y de pensar (lógos) ${ }^{13}$, por ello mismo - continúa diciendo Aristóteles en el mismo lugar- posee el sentido del bien,

12 Se refiere a la Academia (cf. Platón, República IX, 580d_e; Timeo, 69c-72b).

13 Aristóteles concede a los animales superiores no humanos la facultad de la 'representación' (phantasía). También reconoce en alguno de ellos cierta 'inteligencia práctica' (phrónêsis) y otro tipo de cualidades que se relacionan con la inteligencia -véanse: Labarrière (1990), Osborne (2007, pp. 6397) y, sobre todo, Sorabji (1993, passim). 
lo justo y los demás valores (cf. Pol. I 2, 1253a 9-14). El ser humano es, también, el único "capaz de recordar" (HA I 1, 488b 25-29). El único de entre todos los animales pedestres que "tiene más grandes los pies en proporción a su tamaño" ( $P A$ IV 10, $690^{a}$ 27-28). El único que "se sostiene erguido" (ibid. 29). El único que no necesita de los miembros delanteros, siendo único también al estar provisto de "brazos y manos" (ibid. 687 7-8). El único que adquiere la "experiencia [empeirías]", y ello gracias al "arte [téchnê] y los razonamientos [logismoîs]" (Metaph. I 1, 980b 25-27). El único animal capacitado para hacer o "actuar [práxeôn]" (Ética Eudemia [EE] II 6, 1222b 18-20). El único capacitado para "la risa" (PA III 10, 673a 8-10). El único capaz de captar "los olores que son agradables por sí mismos" (Acerca de la sensación y de lo sensible V, 443b 19-20). El único que tiene la capacidad del "lenguaje articulado [diálektos]" (HA IV 9, 536 b 3-4). Por eso mismo el hombre posee un órgano de la lengua "más suelta y más blanda" que el resto de los animales lenguados; y por la misma razón, está también mejor capacitado no sólo para el habla articulada sino, además, para desarrollar el sentido del gusto (cf. PA II 17, 660 18-25). El humano es, en fin, el único de los animales que "participa de lo divino, o el que más de todos" (ibid. II 10, 656 6-7).

En realidad, todas estas especialidades que posee la naturaleza humana se explican por una sola, la facultad de hablar-inteligir (lógos), e incluso esto tiene una explicación fisiológica, como vamos a ver a continuación. El que el ser humano se constituya en el único viviente que camina erguido se explica, desde luego por su peculiaridad bípeda, pero en último término, porque es un ser inteligente. Lo mismo cabe decir respecto de sus manos. Aristóteles sostiene que los humanos tienen manos porque son inteligentes, y no al contrario como creía Anaxágoras (cf. PA IV $\left.10,687^{\mathrm{a}} 8-10\right)$.

El habla humana tiene su causa -insisto- en el pensamiento. Lo demuestra la propia estructura fisiológica del cuerpo humano, como deja en claro el Corpus. Cuando trata sobre los sonidos que emiten los distintos seres vivos, Aristóteles distingue en primer lugar: la 'voz' (phonế) del simple 'ruido' (psóphos) -cf. HA IV 9, $535^{\text {a }}$ 27-28. Éstos, a su vez, se distinguen del 'lenguaje articulado' (diálektos). En Acerca del alma (II, 8, 420b 6-7) leemos que "la voz es un tipo de sonido exclusivo del ser animado". Sin embargo, no todos los vivientes tienen voz; la poseen en exclusivo aquellos animales "que reciben aire en su interior", es decir, los que están naturalmente dotados por el órgano respiratorio de la laringe, y cuyo funcionamiento "está al servicio de otra parte, a saber, el pulmón" (ibid., 22-24). Aristóteles desconocía que los órganos humanos que posibilitan el habla son el cerebro y el aparato fonador, y dentro de este último, es la peculiar posición de la laringe, mucho más baja que la del resto de primates, lo que explica la misma. Con relación a las especies animales, sólo los sanguíneos tendrían la capacidad de emitir voces, salvo los peces (cf. ibid., 10-12). Así que, no todos los animales están dotados por natu- 
raleza de voz. Pero como hemos indicado, Aristóteles también distingue la voz de las expresiones lingüísticas humanas o el lenguaje, con lo que no todos los seres animados que puedan emitir voces poseerán este don natural. En Reproducción de los animales (V 6, 786b 20-21), expresa que los humanos, dado que la naturaleza les ha concedido esa facultad, "son los únicos animales que se sirven de la palabra [lógô]". De nuevo, Acerca del alma (II, 420b 27-31) establece que "el golpe de aire inspirado" es lo que se llama "voz", pero matiza -y debemos pensar exclusivamente en el viviente dotado de voz: "no todo sonido del animal es voz", y lo que no es voz ni lenguaje articulado habrá de ser, por exclusión, ruido. Cabe, "en efecto, producir sonidos con la lengua así como tosiendo"; dicha emisión sonora o golpe del aire sólo será ruido. Y explica:

Ha de ser necesariamente un ser animado el que produzca el golpe sonoro y éste ha de estar asociado a alguna representación [sêmantikòs], puesto que la voz es un sonido que posee representación (ibid., 31-34).

En Sobre la interpretación [Int.] (2, 16 19), lo "significativo [sêmantikée", distingue la voz de un ruido que pueda producir el animal. Esto mismo que Aristóteles explica de la voz del animal es lo que también dice del ser humano. En el mismo pasaje de Sobre la interpretación, sostiene que únicamente "el sonido" que es "significativo" será un "nombre [ónoma]" y, en un sentido que recuerda a la postura que mantiene Hermógenes en el Crátilo de Platón, será "significativo por convención [synthếken]", es decir, que "ninguno de los nombres lo es por naturaleza" (Int., 2728). Para Aristóteles la 'palabra' (ónoma) sólo llega a ser significativa mediante un acuerdo, y por consiguiente, como creía Hermógenes en el Crátilo, nada existe en la palabra que remita naturalmente a su significado. Ya que aludimos a este diálogo de Platón debería recordarse también que Sócrates ponía en un serio aprieto a su interlocutor Hermógenes; Sócrates (cf. Crátilo [Cra.] 385d-e) llegaba a preguntarle si el acuerdo podía desembocar en un pacto privado, con lo cual el lenguaje sólo sería comunicable a las partes que lo pactaron y que lo conocen. Aristóteles salva la objeción platónica remitiendo al uso que legitima los significados de las palabras (cf. Tópicos I 1, 100b 22, respecto de los enunciados plausibles), y como ha enfatizado Anne Cauquelin (1990, pp. 62-63), en todo caso, es la polis el marco que sirve de limitación a esa arbitrariedad de la que habla el Sócrates platónico. De esta forma, el discurso o "enunciado [lógos]" es significativo "no como un instrumento <natural $>$, sino por convención" (Int., 4, 17 1-2), y quedan fuera de dicha consideración enunciativa "los sonidos inarticulados, por ejemplo, de los animales, [pues] ninguno de los cuales es un nombre [ónoma]" (ibid., 28-29). En la Poética [Po.] (20, 1456b 23-24), al hilo que define la primera de las partes del lenguaje (la letra), Aristóteles - hablando en primera persona- reconoce que las bestias "emiten sonidos indivisibles, pero a ninguno de tales sonidos los denomino letras". Como lo 
había expresado respecto de la tos, se entiende como 'sonido' o 'voz' aquello que no sea propiamente lengua articulada. Recuérdese una vez más el criterio rigorista que Crátilo sostiene en el mentado diálogo platónico. Crátilo era valedor del naturalismo lingüístico, que conducía al extremo de considerar "ruido" al que habla en vano o lo hace en falso -Cra. 429b-430a . Es decir, para Crátilo aquél que habla según alguno de estos dos casos no lo hace en absoluto, sus palabras no son tales, y en nada se diferenciarían del ruido que produce un objeto inanimado al ser gol-peado.

En suma, la polis constituye el marco delimitador de las convenciones lingüísticas de los seres humanos. Pero lo es también de cualquier convención humana, y en un sentido teleológico. Así, por medio del lenguaje-pensamiento, los humanos determinamos cuál es el sentido del bien, qué es lo justo y lo injusto, y los demás valores, tal como se desprende del pasaje antes aludido de la Política (cf. I 2, 1253 9-14). Es la naturaleza cívica de los humanos como ciudadanos o 'vivientes cívicos' (politikòn zôon) lo que explica la existencia y la 'realización' misma (télos) de la ciudad (la cual existe por naturaleza), y dicha realización supone la 'vida buena' (eu zên). Para Aristóteles, continúa rigiendo el principio que preside su ciencia natural: el todo (la polis) es anterior a las partes (individuos). Esto es lo que se ventila en el libro I de la Política, y se condensa en los dos pasajes que vamos a considerar a continuación, ambos extraídos del capítulo 2. En el primero de ellos se dice:

La comunidad perfecta de varias aldeas es la ciudad [pólis], que tiene ya, por así decirlo, el nivel más alto de autosuficiencia [autarkeías], que nació a causa de las necesidades de la vida, pero subsiste para el vivir bien [eu zên]. De aquí que toda ciudad es por naturaleza [diò pâsa pólis phýsei éstin], si también lo son las comunidades primeras. La ciudad es el fin de aquéllas, y la naturaleza es el fin [télos gàr aútê ekeínon, hế dè phýsis télos estín]. En efecto, lo que cada cosa es, una vez cumplido su desarrollo, decimos que es su naturaleza [oîon gàr hekastón esti tês genéseôs telestheistês, taútêr phanèn tền phýsin eînai hekástou], así de un hombre, de un caballo o de una casa.

De todo esto es evidente que la ciudad es una de las cosas naturales, y que el hombre es por naturaleza un animal cívico ${ }^{14}[k a i<e k>$ toúton oûn phanetòn hóti tôn phýsei hế pólis ésti, kai hóti hó ánthrôpos phýsei politikòn zôon], y que el incívico [ápolis] por naturaleza y no por azar es o un ser inferior [phaulós] o un ser superior al hombre [kreitôn hề ánthrôpos]. Como aquel a quien Homero vitupera: 'sin tribu, sin ley, sin hogar' (Pol. I, $21252^{\mathrm{b}} 27-1253^{\mathrm{a}}$ 5).

Si la polis acaba conformando un conjunto de convenciones 'artificiales' - a la manera del sofista Protágoras- parece contradictorio que Aristóteles mantenga, a la vez, que la polis exista por naturaleza. Ernest Barker intentó soslayar este salto entre 'naturaleza' y 'convención' en la sociología aristotélica de la ciudad aprovechando

14 Nótese que, en este punto, modifico ligeramente la traducción de Manuela García Valdés: "cívico" e "incívico", en vez de "social" e "insocial". 
la analogía entre el legislador como 'técnico' (technikós) o 'artífice' del gobierno y las leyes de la polis a la que el propio Aristóteles se refiere varias veces en la Política, y escribió que "el arte coopera con la naturaleza" (Barker 1946, p. 7, n. 1). En alusión a la tendencia [hormè] natural de la sociabilidad humana (cf. (Pol. I 2, $1253^{a}$ 29), Barker continúa diciendo: "es la voluntad y la acción de los actores humanos quienes construyen la polis en cooperación y con un impulso natural inmanente" (id.). Bernard Yack (1993, p. 95) ha sostenido más recientemente que "la polis, aunque es un todo y existe por naturaleza, no es un todo natural" e insiste en que la propia naturalidad del ser humano es la que hace natural a la polis. No obstante, la Política no dice en ningún sitio que la polis devenga natural o sea natural de manera sobrevenida, sino que es natural per se "si también lo son las comunidades primeras". Esto es lo que se desprende claramente del texto que acabo de dar y en el que viene a continuación -en ambos he cuidado de dar más que en cualquier otro caso las palabras del griego.

Será la naturalidad del ser humano como viviente cívico la que ocupe la última de nuestras consideraciones. 'Autárquico' en sentido propio no es el individuo sino la polis. El ciudadano sin la polis quedaría solo y aislado - dice de forma gráfica Aristóteles- como una ficha de un tablero de damas (cf. ibid. 6). Una ficha aislada fuera de su casilla no es nada ${ }^{15}$. Igual que a la ficha aislada le sucede al viviente cívico desde el momento en que se convierte o pasa a ser un individuo sin la polis:

Por naturaleza, pues, la ciudad es anterior a la casa y a cada uno de nosotros, porque todo es necesariamente anterior a la parte [kaì próteron dè tê phýsei pólis hề oikia kaì hékastos hêmôn éstin, tò gàr hólon próteron anankaîon eînai toû mérous]. En efecto, destruido el todo ya no habrá ni pie ni mano, a no ser por nombre equívoco [homôný$m o s]$, como se puede decir de una mano de piedra; pues tal será una mano muerta.

Todas las cosas se definen por su función [érgô] y por sus facultades [dynámei], de suerte que cuando éstas ya no son tales no se puede decir que las cosas sean las mismas, sino del mismo nombre [homốnyma]. Así pues, es evidente que la ciudad es por naturaleza y es anterior al individuo [hóti mèn oûn hế pólis kaì phýsei kaì próteron hế hékastos]; porque si cada uno por separado no se basta a sí mismo [autárkês], se encontrará de manera semejante a las demás partes en relación con el todo. Y el que no puede vivir en

15 Jean-Pierre Vernant (1987, p. 128, n. 122) escribe esta sabrosísima observación que no puedo ahorrar reproducir:

En la categoría de los juegos que los griegos designaban con el verbo pesseúein, había uno a que denominaban pólis. Según Suetonio (cf. Sobre los juegos de los griegos I, 16), la pólis es también un tipo de juego de dados en el que los adversarios comen las fichas, colocadas como en las damas (petteutikốs) en casillas delimitadas por líneas que se cruzan entre sí. No sin ingenio se llamaba ciudades (póleis) a las casillas así delimitadas, y perros (kýnes), a las fichas que se enfrentaba unas a otras (...) Si Aristóteles, para definir a los individuos ápolis, se refiere a las damas es porque en el juego griego el damero, que delimita las posiciones y los movimientos respectivos de las fichas, es susceptible, como su nombre indica, de representar el orden de la pólis. 
comunidad, o no necesita nada por su propia suficiencia, no es miembro de la ciudad, sino como16 una bestia o un dios [hốste hề thêrion hề theós] (ibid. I 2, 1253ª 20-28).

Aristóteles aplica aquí como en otras ocasiones su teoría de la homonimia, y es importante destacar que lo hace tal como se refiere en el pasaje de las Categorías en el que nos detuvimos páginas atrás. Por tanto, un viviente cívico sin la polis sólo conservará de ciudadano la palabra. Christopher Schields (2007, p. 354) se ha lamentado que en estas líneas del texto de la Política Aristóteles haga unas "consideraciones extremas", como si se tratara de que el Estagirita hubiese hecho añicos su, otrora, habitual contención. Schields alega que sostener que la autonomía natural del "estado", la polis, subsume al individuo es -qué duda cabe- "de difícil crédito" (ibid., p. 355). La aplicación de la homonimia en este caso conduce, a juicio de Schields, a la disolución o la anulación del ciudadano como ser humano. Él escribe literalmente:

Todavía resulta más extrema la consideración [sc. aristotélica] de que el ser humano [ $s c$. ánthrôpos] que no es miembro de la polis es sólo humano por homonimia (id.).

Por mi parte, soy incapaz de leer esto último en el pasaje anterior de la Política al cual está aludiendo Schields, o también en el que hemos visto antes, en donde se cita el verso de Homero (cf. Ilíada IX, 63), y que de igual modo (aunque sin la referencia a la homonimia) acaba hablando de los dos tipos de seres que no pueden llegar a conocer la polis, ni por tanto vivir una vida buena (los seres inferiores al hombre: las bestias) o los que no requieren ni necesitan de la vida cívica (los seres superiores al hombre: los dioses). Un comentario como el de Schields pervierte totalmente el texto aristotélico ${ }^{17}$. Aristóteles emplea el recurso de la homonimia de la mano hecha de piedra y de la mano del cadáver a modos de ejemplo. Pero esto no da derecho a decir que el ciudadano sin la polis o el 'ciudadano' sólo por el nombre sea igual que una estatua de piedra con forma humana, un cadáver o -como pretende Schields- un ser 'esencialmente' no humano. El juego de la homonimia es -lo reitero: el ciudadano (politếs) sin la polis sólo es ciudadano por el nombre. Pero de ello no puede inferirse que el ciudadano es un 'ser humano' (ánthrôpos) sólo por el nombre.

Sin referirse a la homonimia del ciudadano sin la polis al modo que lo hace Schields, David Keyt se escandaliza también porque Aristóteles haya reducido al

\footnotetext{
16 La traducción que venimos siguiendo de M. García Valdés olvida el adverbio "como [hốste]" en la línea 28. Según se verá a continuación hốste resulta un matiz importante en la interpretación del párrafo.

17 Este es el juicio que le merece a Geoffrey Lloyd, según me ha trasladado en una comunicación privada.
} 
ciudadano sin la polis a una bestia o lo convierta en un dios, sin percibirse de que el texto de la Política establece solamente una comparación con los seres no humanos (bestias o dioses): "como una bestia o un dios [hốste hề thêrion hề theós]" (Pol. I $\left.2,1253^{\text {a }} 28\right)$. Keyt objeta concretamente: "esta consecuencia ( $s c$. la no humanidad) resulta falsa teniendo a la vista los propios principios aristotélicos" (Keyt 1991, pp. 139-140). Nosotros mismos lo hemos explicado al inicio cuando tratamos sobre la zoología aristotélica. Un ser humano no podría convertirse en una bestia o en un dios, por mucho que los mitos cuenten otra cosa. En la mente de Aristóteles un pez siempre será un pez, un ave siempre un ave o un humano siempre un humano (cf. Ph. II 2, 194b 9-13; ibid. 7, 198 24-27; Acerca de la juventud y de la vejez, de la vida y de la muerte, y de la respiración 20, 477b 5-7: en contra del 'evolucionismo' de Empédocles). Pero, en relación con lo que plantea Keyt, no debe perderse de vista que Aristóteles sólo ha establecido una comparación entre el humano-ciudadano y las bestias o los dioses, y que por tanto no se cambia el estatuto ontológico del hombre por aproximarse a uno de los dos vivientes no humanos. Filoctetes, el héroe protagonista de la tragedia de Sófocles a la que da nombre, proporciona una explicación de por qué el humano-ciudadano no puede metamorfosearse en una bestia infrahumana. Sabemos de la preferencia aristotélica por el tragediógrafo Sófocles (cf. Po. 3, 1448 a 26); además, el Filoctetes se amolda al prototipo que el mismo Aristóteles concibe de tragedia 'ética' o de carácter (cf. ibid. 6, 1450a 6-7). Keyt también propone a este héroe tesalio como ejemplo para justificar su propia posición a favor de la incoherencia del pasaje de la Política -nada incoherente según acabamos de defender-, pero al constatar ahora que "la incapacidad de Filoctetes de vivir en la polis carece de la entidad para destruir su humanidad" (id.), sólo está haciendo parcialmente hincapié en el tipo de dilatada experiencia vivida por Filoctetes en el drama sofocleo. Sin duda, como afirma Keyt, la imposibilidad de que Filoctetes pueda vivir cívicamente en la isla de Lemnos no le convierte en una bestia, destruyendo su humanidad, pero esto solamente se aprecia -como pretendemos advertir- en el éxodo, al final de la tragedia, es decir, cuando aparece Heracles divinizado como deus ex machina y Filoctetes es devuelto a la civilidad, por tanto cuando comprende que debe partir hacia Troya y dejar a un lado su antiguo resentimiento por los Átridas (Agamenón y Menelao) y Odiseo -a quienes culpabilizó de su confinamiento en la isla. Los atenienses que tuvieran la ocasión de ver y oír la representación de esta pieza teatral estrenada en el año 409 a. de n. e. conocían (antes que por Sófocles) que el arco de Filoctetes iba a ser el que daría muerte al troyano Paris y pondría fin a la guerra. Por tanto, ellos también sabían que, a pesar de tanta desventura y desolación, Filoctetes volvería a gozar de los beneficios de una 'vida buena'. El diálogo que mantiene Filoctetes con Neoptólemo deja traslucir todo este sufrimiento del héroe durante los diez años trascurridos en Lemnos desde que fue abandonado por los griegos. La razón de su abandono se 
debió al hedor que desprendía la supuración de la herida que le había provocado una picadura de serpiente en las tierras de Crisa y que resultaba insoportable a todos. Filoctetes, por tanto, narra en primera persona las vivencias propias de un ciudadano aislado sin la polis, en una tierra extranjera. La analogía que utiliza Aristóteles en la Política comparando al ciudadano sin la polis con una bestia cobra entonces pleno sentido. Por cierto que, para ganar en dramatismo, la isla de Lemnos aparece en la pieza trágica sofoclea como un lugar agreste e inhóspito, y ello nada más el empiece (cf. Filoctetes 3). El contraste es brutal, dado que al tiempo que Sófocles sienta esta 'arqueología' de la historia troyana, Lemnos no era ni mucho menos un sitio desabrido sino una isla 'griega' tal como la habían caracterizado antes Homero (cf. Ilíada VII, 467) y las otras sagas trágicas perdidas de Esquilo y Eurípides que también se referían al infortunio padecido por el héroe tesalio (cf. Vidal-Naquet 1987, p. 166). Lemnos tenía una importante tradición cultural y religiosa. Los mitos y los ritos vinculaban la volcánica Lemnos con una divinidad relacionada con el fuego por la cual el demos ateniense sentía, además, una gran devoción: el dios artesano Hefesto (cf. Burkert 1970, pp. 1-16). Así, en esta Lemnos pintada como un érêmos es en la que Filoctetes, como si hubiese sido un niño no reconocido por un padre, sufre el mentado abandono o exposición (cf. Filoctetes 703). Sin la polis, Filoctetes se convierte en un asilvestrado (cf. ibid. 226, 1321). Sus quejidos ocasionados por la terrible herida le parecen a Neoptólemo "ruidos" (ibid. 206). Filoctetes no recolecta para sí alimento alguno sino que come como un salvaje. En su dieta están ausentes el cereal y el vino, que son muestra de la vida civilizada (cf. ibid. 708-710, 715) y su hogar está dispuesto en una cueva montaraz como la de las alimañas (cf. ibid. 954, 1087, 1149). Cuando se cree engañado por Neoptólemo, Filoctetes invoca a los animales salvajes, los cuales le han acompañado tanto tiempo (cf. ibid. 936-937, 1145-1146). En suma, el héroe es "un muerto entre los vivos" (ibid. 1019), esto es, glosa Pierre Vidal-Naquet (1987, p. 171), un cadáver social. Volviendo a Aristóteles, puede comprenderse que un ciudadano como Filoctetes en Lemnos lo sea por homonimia, y que se parezca más a las bestias que a un hombre civilizado. Inmediatamente después del último de los dos textos que he dado de la Política sentencia:

El hombre perfecto es el mejor de los animales, así también, apartado de la ley y de la justicia, es el peor de todos (Pol. I 2, 1253 36).

En la Ética nicomáquea (cf. VII 1, 1145 15-19) se distinguen tres clases de disposiciones del carácter que deben evitarse: el vicio (kakía), la incontinencia (akrasía) y la brutalidad (thêriótês). Richard Bodéüs (1997, pp. 248-249) ha enfatizado que sólo la última es una disposición propia del viviente ápolis. Mientras las dos primeras son dos clases de deficiencias del ser humano cívico, la brutalidad es propia del incívico, del humano que peligrosamente se acerca a la vida de los animales 
no humanos, en quienes "no puede darse vicio ni virtud"18 (EN VII 1, 1145'26). Sin embargo, el bruto no podrá dejar de ser un ánthrôpos, por más que su carácter o sus costumbres sean propios de un animal salvaje. Después de lo que hemos expuesto en relación con el habla humana y el calado que adquiere el lógos creo que puede comprenderse cuán significativo es que al propio Filoctetes después de diez años solo en la isla le mueva el deseo por hablar y de escuchar-según le hace decir Sófocles- el "queridísimo lenguaje" (Filoctetes 235).

\section{Coda}

Hemos llegado al final de este recorrido por el pensamiento de Aristóteles y su concepción del ser humano. Aunque sea obvio decirlo, el nuestro no pretende ser ni mucho menos un estudio completo sobre un tema que es vastísimo. Entre las carencias de que adolece se encuentra una ausencia importante - a buen seguro alguien puede haberlo echado en falta. Me refiero al peculiar tratamiento que el Corpus hace de la alteridad, es decir, las diferencias que presenta el génos humano (sexo, edad y raza, principalmente). Los seres vivos de un mismo 'género' (génos) pueden diferir en cuanto a sus tipos de vida; de este modo, habrá diferencias entre un animal doméstico y otro de la misma clase que viva en estado salvaje (cf. Bostock 2006, p. 89), y las habrá también entre humanos griegos y los bárbaros (cf. Aristóteles, Pol. I, passim; VII, 7). No sólo esto, habría que distinguir además entre las formas humanas individuales entre sí, pues, aun siendo griegos, Corisco no es Sócrates (cf. GA IV 3, 767b 24-768 2 2; Bostock 2006, pp. 92-93, 100). Por su parte, la diferenciación sexual nos habría obligado a tener que referirnos a la teoría aristotélica de la reproducción animal, y una vez puesto en evidencia los diferentes factores naturales que hacen diferenciarse a un hombre de una mujer podrían haberse tratado las diferencias fisiológicas que presenta el habla en los niños y en las mujeres. Adviértase que la espinosa cuestión de la esclavitud natural también se halla en directa relación con el grado de inteligencia más o menos defectuoso que poseen los bárbaros.

Espero, al menos, haber ofrecido una caracterización general del ánthrôpos aristotélico, si bien, afirmado esto y a la vista de lo expuesto en la última parte no hay duda de que al ser humano debe identificársele en sentido estricto con el humano 'maduro' o ‘completo' (téleios), que en términos sociológico-políticos lo constituye el ciudadano (politếs). El propio libro I de la Política establece un nexo muy claro entre el varón, por naturaleza libre, de raza griega, el cuál es también el 'prudente' u hombre 'sagaz' (phrônistếs), objeto de las Éticas.

18 He modificado ligeramente la traducción de Julio Pallí Bonet. 
Por último, nos habríamos complicado en demasía si, además de tratar al pensamiento aristotélico, hubiéramos optado por hacerlo comparándolo con otras fuentes del período clásico griego o incluso del anterior. No obstante, en algunas ocasiones, he optado por romper este criterio, como se ha visto en los casos de las referencias a los mitos y los cuentos fabulosos de los griegos, o en la remisión que al final acabo de hacer al Filoctetes de Sófocles. Pero quedaría todavía un mar de posibilidades. Basten estas dos últimas referencias contextuales que pueden ayudar a acabar de perfilar nuestra presentación del ánthrôpos aristotélico; con ellas concluimos. Pese a los prejuicios misóginos de los que pueda en justicia achacársele a Aristóteles, en el Corpus no hay rastro del uso peyorativo hế ánthrôpos, 'la humana'. Joshua Sosin (1997, p. 75-83) ha ilustrado cómo en las fuentes del período clásico el empleo de la forma nominal hế ánthrôpos casi siempre posee una connotación semántica despectiva. Además, y pese a que Aristóteles tradicionalmente constituye el paradigma clásico teórico del humano como ser racional, en su tiempo no fue nada revolucionario el hecho de asimilar ánthrôpos con 'ser inteligente' o 'racional' (zôon logikòn); esta terminología estaba ya presente en los pitagóricos y en Platón (cf. Renehan 1981, pp. 240-241). Tampoco, Aristóteles fue -si se me permite la licencia- el primer racionalista avant la lettre. Como es bien conocido, uno de sus grandes predecesores, Anaxágoras, había convertido al nous en la piedra de toque de sus especulaciones naturales. A Anaxágoras aludimos al tiempo que Aristóteles le refutaba la interpretación de que el hombre es inteligente porque posee manos.

\section{Referencias bibliográficas}

ACKRILl, J.L. (1997): Essays on Plato and Aristotle, Oxford, Clarendon Press.

ARISTÓTELEs (1982): Tratados de lógica (Órganon) I: Categorías. Tópicos. Sobre las refutaciones sofisticas, trad. M. Candel, Madrid, Gredos.

Aristóteles (1983): Acerca del alma, trad. T. Calvo, Madrid, Gredos.

Aristóteles (1985): Ética nicomáquea. Ética eudemia, trad. J. Pallí, Gredos, Madrid.

ARISTÓTELES (1987): Acerca de la generación y la corrupción. Tratados breves de historia natural (Acerca de la sensación y de lo sensible. Acerca de la memoria $y$ de la reminiscencia. Acerca del sueño y de la vigilia. Acerca de los ensueños. Acerca de la adivinación por el sueño. Acerca de la longevidad y de la brevedad de la vida. Acerca de la juventud y de la vejez, de la vida y de la muerte, y de la respiración), trad. E. La Croce / A. Bernabé, Madrid, Gredos. Aristóteles (1988): Política, trad. M. García Valdés, Madrid, Gredos.

ARISTÓTELes (1990): Investigación de los animales, trad. J. Pallí, Madrid, Gredos. ARISTóteles (1994): Reproducción de los animales, trad. E. Sánchez Millán, 
Madrid, Gredos.

ARistóteles (1995): Física, trad. G.P. de Echandía, Madrid, Gredos.

Aristóteles (1998): Metafísica, trad. T. Calvo, Madrid, Gredos.

ARISTóteles (2000a): Partes de los animales. Marcha de los animales. Movimiento

de los animales, trad. E. Jiménez / A. Alonso, Madrid, Gredos.

ARISTÓTELes (2000b): Sobre las líneas indivisibles. Mecánica / Euclides: Óptica.

Catóptrica. Fenómenos, trad. P. Ortiz, Madrid, Gredos.

Aristóteles (2005a): Poética, trad. S. Mas, Madrid, Biblioteca Nueva.

ARIstóteles (2005b): Fragmentos, trad. A. Vallejo, Madrid, Gredos.

BALme, D.M. (1986): “The place of biology in Aristotle's philosophy”, en A. Gotthelf / J.G. Lennox (ed.), op. cit., pp. 5-20.

BARKer, E. (1946): The Politics of Aristotle, Oxford, Clarendon Press.

BAYER, G. (1998): "Classification and explanation in Aristotle's theory of definition", Journal of the History of Philosophy, 36, pp. 487-504.

BERRYMAN, S. (2007): "The imitation of life in ancient Greek thought", en J. Riskin (ed.), Genesis redux: Essays in the history and philosophy of artificial life, Chicago, The University of Chicago Press, pp. 35-45.

BoDÉÜs, R. (1997): "Les considérations aristotéliciennes sur la bestialité : traditions et perspectives nouvelles", en B. Cassin / J.-L. Labarrière (ed.), L'Animal dans l'Antiquité, Paris, Vrin, pp. 247-258.

Bostock, D. (2006): Space, time, matter, and form: Essays on Aristotle's Physics, Oxford, Clarendon Press.

BuRNYEAT, M.F. (1995a): "Is an Aristotelian philosophy of mind still credible? (A draft)", en M.C. Nussbaum / A.O. Rorty (ed.), op. cit., pp. 15-26.

BuRnYEAT, M.F. (1995b): "How much happen when Aristotle sees red and hears middle C?", en M.C. Nussbaum / A.O. Rorty (ed.), op. cit., pp. 421-434.

BurkerT, W. (1970): "Jason, Hypsipyle, and the new fire at Lemnos: A study in myth and ritual", Classical Quarterly, 20, pp.1-16.

Cauquelin, A. (1990) : Aristote: le langage, Paris, Presses Universitaires de France.

CLARK, S.R.L. (1975): Aristotle's man: Speculations upon Aristotelian anthropology, Oxford, Clarendon.

Code, A. / J. Moravcsik (1995): "Explaining various forms of life", en M.C. Nussbaum / A.O. Rorty (ed.), op. cit., pp. 129-146.

Frede, M. (1995): “On Aristotle's conception of the soul”, en M.C. Nussbaum / A.O. Rorty (ed.), op. cit., pp. 93-107.

Frey, C. (2007): "Organic unity and the matter of man", Oxford Studies in Ancient Philosophy, 32, pp. 167-204.

FurTh, M. (1988): Substance, form, and psyche: An Aristotelean metaphysics, Cambridge, Cambridge University Press. 
GiLl, C. (1990): "The human being as an ethical norm", en C. Gill (ed.), The person and the human mind: Issues in Ancient and Modern philosophy, Oxford, Clarendon Press, pp. 137-161.

GotThelf, A. / J.G. Lennox, ed. (1986): Philosophical issues in Aristotle's biology, Cambridge, Cambridge University Press.

Heinaman, R.E. (1979): “Aristotle's tenth aporia“, Archiv für Geschichte der Philosophie, 61, pp. 249-270.

Herzen, A.I. (1956): Sobranie sochineniǔ, vol. vi, Moskva, Nauka.

Homero (1982): Odisea, trad. J.M. Pabón, Madrid, Gredos.

Homero (1993): Ilíada, trad. A. López Eire, Madrid, Cátedra.

Johnson, M.R. (2005): Aristotle on teleology, Oxford, Clarendon Press.

KeYt, D. (1991): "Three basic theorems in Aristotle's Ethics and Politics", en D.

Keyt / F. Miller jr. (ed.), A companion to Aristotle's Politics, Oxford, Blackwell, pp. 118-141.

KRIS, E. / O. Kurz (1934): Die Legende von Künstler: Ein gesichtlicher Versusch, Wien, Krystall Verlag.

LABARRIÈRE, J.-L. (1990): "De la phronesis animale", en D. Deveraux / P. Pellegrin (ed.), Biologie, logique et métaphysique chez Aristote, Paris, Centre National de la Recherche Scientifique, pp. 405-428.

Laín entralgo, P. (1987): La medicina hipocrática, Alianza, Madrid.

LENNOX, J.G. (1986): "Kinds, forms of kinds, and the more and the less in Aristotle's biology", en A. Gotthelf/ J.G. Lennox (ed.), op. cit., pp. 339-359.

LenNox, J.G. (2001): Aristotle's philosophy of biology: Studies in the origins of life science, Cambridge, Cambridge University Press.

LLOYD, G.E.R. (1986): "Empirical research in Aristotle's biology", en A. Gotthelf / J.G. Lennox (ed.), op. cit., pp. 53-63.

Lloyd, G.E.R. (1995): Aristotelian explorations, Cambridge, Cambridge University Press.

Nussbaum, M.C. / A.O. Rorty, ed. (1995): Essays on Aristotle's De anima, Oxford, Clarendon Press.

Nussbaum, M.C. / H. Putnam (1995): "Changing Aristotle's mind", en M.C. Nussbaum y A.O. Rorty (ed.), op. cit., pp. 27-56.

Osborne, C. (2007): Dumb beasts and dead philosophers: Humanity and the humane in Ancient philosophy and literature, Oxford, Clarendon Press.

Ovidio (1995): Metamorfosis, trad. C. Álvarez / R.Mª Iglesias, Madrid, Cátedra.

Pellegrin, P. (1982): La Classification des animaux chez Aristote: Statut de la biologie et unité de l'aristotélisme, Paris, Les Belles Lettres.

PíndARo (1988): Obra completa, trad. E. Suárez, Madrid, Cátedra.

Platón (1983): Diálogos II (Gorgias. Menéxeno. Eutidemo. Menón. Crátilo), trad. J. Calonge Ruiz / E. Acosta Méndez / F.J. Olivieri / J.L. Calvo, Madrid, Gredos. 
Platón (1986): Diálogos IV (República), trad. C. Eggers, Madrid, Gredos.

Platón (1992): Diálogos VI (Filebo. Timeo. Critias), trad. Ma .A. Durán /F. Lisi, Madrid, Gredos.

RENEHAN, R. (1981): “The Greek anthropocentric view of man", Harvard Studies in Classical Philology, 85, pp. 239-259.

SchiEldS, C. (1999): Order in multiplicity: Homonymy in the philosophy of Aristotle, Oxford, Clarendon Press.

SCHIELDS, C. (2007): Aristotle, London, Routledge.

Sedley, D. (1990): “Is Aristotle's teleology anthropocentric?”, Phronesis, 36, pp. $179-196$.

SÓfocles (1981): Tragedias, trad. A. Alamillo, Madrid, Gredos.

SORABJ, R. (1993): Animal minds and human morals: The origins of the Western debate, Ithaca, Cornell University Press.

Sosin, J.D. (1997): “A word for women?", Greek, Roman, and Byzantine Studies, 38, pp. $75-83$.

Vernant, J.-P. / P. Vidal-Naquet (1987), Mito y tragedia en la Grecia antigua I, trad. M. Armiño, Madrid, Taurus.

VERnANT, J.-P. (1987): “Ambigüedad e inversión sobre la estructura enigmática del Edipo rey", en J.-P. Vernant / P.Vidal-Naquet, op. cit., pp. 101-133.

VeYne, P. (1983): Les Grecs ont-ils cru à leurs mythes?, Paris, Seuil.

Vidal-Naquet, P. (1987): "El Filoctetes de Sófocles y la efebía”, en J.-P. Vernant / P.Vidal-Naquet, op. cit., pp. 161-187.

Whitting, J. (1995): "Living things", en M.C. Nussbaum y A.O. Rorty (ed.), op. cit., pp. 75-91.

Wiggins D. (1967): Identitity and spatio-temporal continuity, Oxford, Blackwell.

Williams, B.A.O. (1986): "Hylomorphism", Oxford Studies in Ancient Philosophy, 4, pp. 186-199.

YACK, B. (1993): The problems of a political animal: Community, justice, and conflict in Aristotelian political thought, Berkeley, University of California Press.

José Javier Benéitez Prudencio

Departamento de Filosofía

Universidad de Castilla-La Mancha

josejavier.beneitez@uclm.es 